\title{
Service Excellent Berdasarkan Prespektif Islam di Bank Syariah
}

\author{
Danang Kurniawan \\ Institut Agama Islam Negeri Kudus \\ kangkaji95@yahoo.com
}

\begin{abstract}
The effort of Islamic banks in creating and maintaining customers to remain satisfied and loyal is to implement service excellence. Descriptive qualitative research methods by reviewing the literature, books, journals and other references related to the research discussion. The results obtained, that the concept of Islamic banking service excellence consists of three aspects, namely aqidah, morals and muamalah. Al-Qur'an has become a guide in conducting Islamic banking services. Employees must also be able to imitate the Prophet in serving customers when trading (Surat al-Ahzab verse 21). Employees must serve customers with a gentle, forgiving, and a strong determination (Surat Ali Imran verse 159). The bank must also apply the method of propaganda Rasulullah SAW in attracting interest, and fostering customers namely Al-hikmah, Al-Mau'idzah bil Hasanah and Al-Mujadalah Bil Hasanah.
\end{abstract}

Keywords: Excellent Sevice, Islam

\begin{abstract}
Abstrak
Usaha bank syariah dalam menciptakan dan mempertahankan nasabah agar tetap merasa puas dan loyal adalah dengan menerapkan service excellence. Metode penelitian secara deskriptif kualitatif dengan mengkaji literatur, buku, jurnal dan referensi-referensi lain yang terkait dengan pembahasan penelitian. Hasil penelitian yang didapat, bahwa konsep service excellence perbankan syariah terdiri dari tiga aspek yaitu aqidah, akhlak dan muamalah. Al-Qur'an telah menjadi panduan dalam melakukan pelayanan perbankan syariah. Karyawan juga harus bisa mencontoh Rasul dalam melayani pelanggan waktu berdagang (Surat AlAhzab ayat 21). Karyawan harus melayani nasabah dengan lemah lembut, memiliki sifat pemaaf, dan tekad yang kuat (Surat Ali Imran ayat 159). Bank juga harus menerapkan metode dakwah Rasulullah SAW dalam menarik minat, dan membina nasabah yaitu Al-hikmah, Al-Mau'idzah bil Hasanah dan Al-Mujadalah Bil Hasanah.
\end{abstract}

Kata Kunci : Sevice Excellent, Islam

\section{PENDAHULUAN}

Dalam perkembangan dunia modern sistem manajemen semakin meningkat. Perusahaan dituntut memiliki sistem manajemen yang baik sehingga akan memberikan dampak yang signifikan. Adapun tantangan terbesar dalam dunia bisnis salah satunya adalah menciptakan dan mempertahankan pelanggan supaya puas dan loyal. Perusahaan akan dihadapkan dengan permasalahan yang cukup sulit dalam memberikan pelayanan terhadap konsumennya, serta para pesaing juga termasuk salah 
satu bagian dari permasalahan dan harus dihadapi. Maka semua sumber daya manusia, mulai dari direksi sampai clening service, harus bisa memberikan pelayanan prima (service excellent), tentu sesuai dengan tupoksinya masing-masing. Upaya ini dilakukan untuk memberikan dampak baik secara langsung maupun tidak langsung terhadap para konsumen. Survey yang dilakukan oleh Mobius Management Systems telah membuktikan bahwa pelayanan yang buruk menyebabkan $60 \%$ nasabah melakukan pembatalan akun dengan bank dan 35\% berganti penyedia kartu kredit (Finalist 1st IsEFEF:2012).

Dalam rangka meningkatkan kompetensi dan profesionalisme sumber daya manusia (SDM) diperlukan wawasan tentang pelayanan prima. Selanjutnya diharapkan bisa menerapkan pelayanan prima tersebut dalam melaksanakan tugas yang diberikan. Semua pihak di bidang pelayanan, perlu mengetahui dan diberi bekal pengetahuan antara lain untuk: memahami konsep dan standarisasi pelayanan prima, memahami berbagai permasalahan dalam pelayanan prima, memahami berbagai sikap-perilaku yang merupakan cerminan dari pelayanan prima yang harus dilakukan oleh tenaga profesional, makin meningkatkan kemampuan dan kemauannya untuk memberikan pelayanan prima dalam tugas-tugasnya (Firmansyah, $2016: 163$ ).

Standar penilaian pelayanan prima, di perbankan syariah dengan bank konvensional perlu juga ditelusuri kembali terkait hasil yang dicapai. Perbankan syariah harus memiliki parameter dan indikator yang berbeda, karena secara sistem dan filosofi perbankan syariah berbeda dengan perbankan konvensional (Hana, 2018). Nilai nilai yang terkandung dalam Al Qur'an dan hadist menjadi konsep dari perbankan syariah dalam menerapkan pelayanan prima.

Kajian ini bertujuan untuk mengetahui dasar pelayanan prima (service excellence) serta bagaimana konsep pelayanan prima menurut AlQur'an dan implementasi pelayanan prima terhadap nasabah menurut AlQuran. Adapun metode yang digunakan adalah studi kepustakaan dengan pendekatan deskriptif eksploratif.

\section{PEMBAHASAN}

\section{Konsep Dasar Pelayanan Prima (service excellence)}

Pelayanan prima adalah suatu pelayanan terbaik dalam memenuhi harapan dan kebutuhan pelanggan. Dengan kata lain, Pelayanan prima merupakan suatu pelayanan yang memenuhi standar kualitas yang sudah di tentukan (Freddy Rangkuti, 2016 : 49). Bisa diartikan bahwa layanan prima/ service excellence sebuah upaya yang dilakukan oleh para pelaku bisnis dalam memberikan layanan yang terbaik terhadap pelanggan/ konsumen. Freddy Rangkuti (2016 : 49), juga berpendapat bahwa layanan prima atau service excellence bertitik tolak pada upaya pelaku bisnis 
untuk memberikan layanan terbaiknya sebagai wujud kepedulian perusahaan terhadap pelanggan/konsumen.

Menurut Malayu Hasibuan (2002 : 54-58), melakukan pelayanan prima berarti apabila tindakan untuk memenuhi kebutuhan atau permintaan pelanggan telah dilakukan dengan cara-cara yang sangat memuaskan. Kepuasan pelayanan sangat ditentukan pada besarnya harapan pelanggan. Jika harapan pelanggan yang diberikan tidak terlalu besar, maka pelayanan yang baik, sudah bisa dirasakan sebagai pelayanan prima (excellence). Tetapi jika harapan pelanggan sangat tinggi dan pelayanan yang diberikan tidak sesuai dengan harapan, maka pelayanan yang sama, bisa diartikan sebagai pelayanan yang buruk. Oleh sebab itu, pelayanan prima selalu memiliki tolok ukur sesuai standar baku yang berlaku secara umum.

Konsep dimensi standar pelayanan prima (service excellence), menurut Riyanto, (2012 : 221) setidaknya ada lima kriteria pokok

kualitas pelayanan sebagai berikut :

1. Berwujud (tangible)

Definisi Operasional / indikatornya dikembangkan berwujud (Tangible) berupa :

a. Memiliki peralatan dan tehnologi mutakhir.

b. Memiliki fasilitas - fasilitas yang menarik secara visual

c. Karyawan berpenampilan rapi dan professional

2. Kehandalan (Reliability)

Kemampuan untuk melaksanakan jasa yang dijanjikan dengan tepat dan terpercaya, cekatan dalam melayani serta tidak menunda-nunda pekerjaan.

3. Keterhandalan (reability)

a. Karyawan memberikan sambutan yang baik pada saat ada jamaah datang.

b. Waktu pelayanan yang disediakan sesuai dengan jadwal yang diinformasikan.

c. Karyawan bersikap simpatik dalam menghadapi masalah / komplain jamaah.

d. Menyediakan layanan sesuai yang dijanjikan.

e. Menyimpan data secara benar dan akurat.

4. Ketanggapan (responsiveness)

a. Selalu memberitahukan mengenai jadwal pelayanan.

b. Memberikan layanan bagi pelanggan dengan cepat dan tepat waktu.

c. Karyawan mau membantu pelanggan didalam kelengkapan administrasi.

d. Karyawan tidak pernah merasa sibuk dalam menangapi permintaan nasabah. 
5. Kompetensi (Competency)

Kemampuan setiap orang dalam suatu perusahaan memiliki keterampilan dan pengetahuan yang dibutuhkan agar dapat memberikan jasa tertentu, meliputi: pengetahuan pegawai tentang produk/jasa yang ditawarkan, keterampilan petugas dalam melayani konsumen dan kecepatan pelayanan.

6. Keyakinan (assurance)

a. Karyawan mampu menanamkan kepercayaan kepada nasabah.

b. Karyawan memberikan rasa aman dalam memberikan layanan terhadap nasabah.

c. Karyawan senantiasa bersikap sopan dan ramah.

d. Karyawan memiliki pengetahuan yang cukup untuk menjawab pertanyaan nasabah.

e. Karyawan dapat dipercaya. Tatakrama (Courtesy)

7. Tatakrama (Courtesy)

Kesopanan meliputi sikap sopan santun, perhatian dan keramahan

8. Kredibilitas (Credibility)

Sifat jujur dan dapat dipercaya.

9. Keamanan (Security)

Aman dari bahaya, resiko, atau keraguan.

10. Akses (Acsess)

Kemudahan untuk ditemui atau dihubungi

11. Komunikasi (Communication)

Memberikan informasi kepada pelanggan dalam bahasa yang dapat dipahami oleh para pelanggan atau jamaah, serta selalu mendengarkan saran dan keluhan pelanggan atau jamaah.

12. Perhatian Kepada Pelanggan (Understanding The Customer)

Usaha untuk memenuhi kebutuhan pelanggan yang meliputi : memberikan saran dan pendapat sesuai dengan kondisi pelanggan, pemahaman terhadap kebutuhan pelanggan dan perhatian khusus terhadap pealanggan.

13. Kepedulian (emphaty)

a. Karyawan memperhatikan terhadap kepentingan nasabah (memberikan konsultasi nasabah). Karyawan tanggap terhadap kebutuhan nasabah yang diinginkan.

b. Karyawan selalu siap merespon permintaan nasabah.

c. Karyawan menangani nasabah dengan penuh perhatian dan kesabaran.

d. Menyediakan tempat layanan yang nyaman dan aman.

Ada beberapa tujuan dan manfaat diterapkannya pelayanan prima (service excellence). Menurut Nina Rahmayanty, (2013 : 12) terdapat beberapa tujuan pelayanan prima yaitu : 
a. Memberikan rasa puas dan kepercayaan pada konsumennya. Kualitas memberikan dorongan kepada pelanggan untuk menjalin hubungan yang kuat dengan perusahaan.

b. Kemudian adanya pelayanan prima tetap menjaga dan merawat pelanggan merasa diperhatikan dan dipentingkan segala kebutuhannya atau keinginannya.

c. Serta upaya mempertahankan pelanggan agar tetap loyal untuk menggunakan produk barang atau jasa yang ditawarkan tersebut.

Adapun beberapa manfaat yang didapatkan atas diterapkannya pelayanan prima adalah sebagai berikut:

a. Meningkatkan Citra Perusahaan

Citra atau nama perusahaan dapat diledakkan dengan sebuah usaha pelayanan prima. Perusahaan yang memberikan layanan bermutu serta mengedepankan atau memprioritaskan pelanggan adalah mereka yang memiliki strategi bertahan dan berkembang. Semakin cepat dan tepat dilakukan pelayanan prima (Service Excellence) maka semakin hebat pula perusahaan itu bangkit.

b. Loyalitas pelanggan atau Nasabah

Loyalitas merupakan keadaan yang bisa dibentuk. Loyalitas merupakan kesetiaan yang bisa dibentuk dari pelanggan kepada perusahaan. Hal ini bisa terjadi karena perusahaan memberikan pelayanan yang dapat memuaskan pelanggan.

c. Memberikan Kesan Baik

Setiap pertemuan antara pelanggan dengan perusahaan bagian Frontliner (CS) pasti menimbulkan kesan. Ketika pelayanan prima (Service Excellence) dilakukan sesuai prosedur perusahaan yang berlaku, pelanggan akan merasa sangat dihargai dan merasa diayomi dengan baik. Dengan demikian kesan yang baik akan didapatkan dan dirasakan manfaatnya oleh perusahaan dari pelanggan.

d. Mendapatkan Timbal Balik Yang Sesuai

Segala aspek yang dilakukan oleh CS selaku garda depan dari perusahaan akan mendapatkan timbal balik yang sesuai dari pelanggannya. Seorang pelanggan yang datang dan mengeluarkan keluhan lalu ditanggapi dengan baik dan bijak oleh CS, maka pelanggan akan membicarakan mutu dan kualitas pelayanan pada publik. (Daryanto dan Ismanto, 2014 : 109).

Menurut Freddy Rangkuti konsep pelayanan prima adalah A6, konsep yang sangat berpengaruh dengan setiap pekerjaan para karyawannya guna memenuhi ekspektasi para nasabah. Dengan menggunakan konsep pelayanan prima diyakini perusahaan mampu memenuhi harapan para pelanggan. A6 dalam pelayanan prima menurut Freddy Rangkuti (2016 : 50-55), yaitu : 
a. Ability (kemampuan)

Pengetahuan dan keterampilan tertentu yang mutlak diperuntukan untuk menunjang program layanan prima.

b. Attitude (sikap)

Perilaku atau perangai yang harus di tonjolkan ketika menghadapi pelanggan. Sikap mencerminkan perilaku atau gerak-gerik yang terlihat dari diri seseorang ketika dia menghadapi situasi tertentu atau ketika berhadapan dengan orang lain

c. Appearance (penampilan)

Penampilan seseorang, baik yang bersifat fisik saja maupun fisik dan nonfisik yang mampu merefleksikan diri dan kredibilitas orang tertentu kepada pihak lain.

d. Attention (perhatian)

Kepedulian penuh terhadap pelanggan, baik yang berkaitan dengan perhatian atau kebutuhan dan keinginan pelanggan maupun pemahaman atas saran atau kritiknya.

e. Action (tindakan)

Kegiatan nyata yang harus dilakukan dalam memberikan layanan kepada pelanggan. Apabila dikaitkan denan pelaksanaan pelayanan, yaitu upaya atau perbuatan nyata yang ditunjukan untuk memberikan pelayanan yang wajar atau pelayanan yang baik.

f. Accountability (tanggung jawab)

Suatu sikap keberpihakan kepada pelanggan sebagai wujud kepedulian untuk menghindarkan atau meminimalkan kerugian atau ketidakpuasan pelanggan.

\section{Konsep pelayanan menurut Al-Qur'an}

Pelayanan dalam perbankan sangatlah penting, karena usaha perbankan erat hubungannya dengan nasabah. Nasabah merupakan sumber utama dalam keberlangsungan usaha, sehingga hubungan bank dengan nasabah harus bisa terjalin dengan baik. Dalam menjalin hubungan dengan nasabah ada tiga konsep dasar pelayanan yang perlu diperhatikan oleh bank syariah yaitu keikhlasan, kesuaian pelayanan dengan syariat, dan berusaha melayani dengan pelayanan terbaik. (M. Zainul Wathani dan Afiati Kurniasih, 2015 : 9)

\section{a. Keikhlasan}

Keikhlasan adalah suatu yang harus dilakukan dalam melakukan amal perbuatan, begitu halnya dalam memberika pelayanan untuk nasabah. Karyawan setiap memberikan pelayanan harus didasari dengan keikhlasan kepada Allah SWT. Pelayanan yang tidak didasari dengan keihklasan walaupun terlihat baik tetapi tidak memiliki arti di hadapan Allah SWT. 
Rasulullah sabdanya : "Dari Abu Qatadah RA, dari Rasulullah SAW, beliau berada di antara para sahabat seraya berkata, 'Sesungguhnya berjuang atau berjihad di jalan Allah dan beriman kepada-Nya adalah sebaik-baik perbuatan." Tiba-tiba seorang lelaki berdiri dan bertanya kepada beliau, "Ya Rasulullah, bagaimana menurut pendapat engkau jika saya terbunuh di jalan Allah, apakah semua dosa saya akan diampuni?" Rasulullah menjawab, "Benar. Apabila kamu terbunuh di jalan Allah dalam kondisi yang sabar dan ikhlas karena-Nya, maka semua dosamu akan diampuni." Lalu Rasulullah SAW bertanya, "Apa pertanyaanmu tadi?' Laki-laki itu mengulangi pertanyaannya, "Ya Rasulullah, bagaimana menurut pendapat engkau jika saya terbunuh di jalan Allah, apakah semua dosa saya akan diampuni?" Rasulullah menjawab, "Benar. Itupun kalau kamu dalam kondisi yang sabar dan ikhlas karena Allah, maka semua dosamu akan diampuni, kecuali utang. Itulah yang disampaikan Jibril kepadaku." ( HR. Muslim).

\section{b. Sesuai dengan Syariat}

Syariat adalah aturan Allah SWT yang mengatur seluruh kehidupan manusia. Syariat berisi tentang panduan mengenai masalah ibadah dan berisi tentang panduan mengenai permasalahan kehidupan manusia. Dalam memberikan pelayanan terhadap nasabah juga harus sesuai dengan syariah dan termasuk produk yang dijual.

Bank-bank syariah saat ini telah berusaha memastikan kehalalan produk perbankan dengan menetapkan Dewan Pengawas Syariah. Dewan Pengawasan Syariah yang akan memeriksa dan menjamin kehalalan produk dengan pertimbangan fatwa yang telah dikeluarkan Dewan Syariah Nasional (DSN) MUI. Ada beberapa prinsip syariah pelayanan yang harus diperhatikan oleh bank syariah, yaitu (Mukinim : 2011) :

1. Prinsip persamaan (Al-Musawah) yaitu tidak membedakan pelayanan terhadap nasabah (QS : Al-Hujarat (26) 13).

2. Prinsip persaudaraan (Ukhuwah) yaitu penyelesaian masalah harus diselesaikan dengan prinsip kekeluargaan (QS : Al-Hujarat (26) 10).

3. Prinsip cinta kasih (Muhabbah) ; bentuk prinsip ini dalam pelayanan misalnya tidak saling menyalahkan ketika ada complain dari nasabah. (QS : Al-Balad (30) 177).

4. Prinsip perdamaian (Silm) misalnya penyelesaian masalah dengan cara non litigasi seperti Badan Arbitrase Syariah Nasional (Basyarnas) (QS : Al-Anfal (11) 61).

5. Prinsip tolong-menolong (At-ta'awun) yaitu menolong kesusahan nasabah (QS : Al-Maidah (6) 1).

\section{c. Melakukan yang terbaik.}

Allah SWT berfirman: "Hai manusia, Sesungguhnya kamu telah bekerja dengan sungguh-sungguh menuju Tuhanmu, Maka pasti kamu akan menemuiNya"(QS : Al-Insyiqaq ; (30) 6). Ayat ini menerangkan perjalanan hidup 
manusia dengan melakukan keras untuk mencapai kesenangan. Maka setiap melakukan aktivitas / pekerjaan harus dilakukan dengan totalitas. Begitu halnya dalam memberikan pelayanan, karyawan harus memberikan pelayanan dengan totalitas. Totalitas pelayanan karyawan disini disamping sesuai dengan SOP yang ditetapkan oleh Bank, tetapi juga harus memberikan kemampuan yang terbaik dan sepenuh hati.

Karyawan harus bisa memberikan nilai tambah untuk perusahaan dan memperhatikan para nasabah ; baik suasana hati, sikap serta perilakunya. Totalitas dalam memberikan pelayanan harus dilakukan oleh karyawan. Hal ini erat hubungannya dengan firman Allah SWT, yaitu : "Hai orang-orang yang beriman, masuklah kamu ke dalam Islam keseluruhan, dan janganlah kamu turut langkah-langkah syaitan. Sesungguhnya syaitan itu musuh yang nyata bagimu (QS : Al-Baqarah (1) 208). Ayat ini menjelaskan bahwa Allah SWT menyeru kepada orang yang beriman untuk masuk kedalam Islam secara keseluruhan (totalitas).

Kesimpulannya adalah ini memiliki arti bahwa kita harus mengamalkan ajaran Islam dengan mengerahkan segenap kemampuan yang dimiliki (Al-Imam Abu Fida (Ibnu Katsi : 2000). Demikian halnya dengan pelayanan yang ada di bank syariah harus diupayakan dengan mengerahkan kemampuan terbaik agar mendapatkan hasil yang sesuai dengan harapan (maksimal).

\section{Pelayanan Prima Terhadap Nasabah Berdasarkan Al-Qur'an}

Apa yang dialami perbankan syariah saat ini hampir sama dengan kondisi dakwah Rasulullah SAW. Dakwah Rasulullah SAW begitu banyak cobaan dan rintangan tetapi pada akhirnya dakwah beliau sangat berhasil. Keberhasilan tersebut tidak bisa lepas dari kecakapan dakwah beliau dalam memikat dan menjalin hubungan dengan baik. Metode dakwah Rasul yang demikan dapat menjadi rujukan bagi Perbankan Syariah untuk memberikan pelayanan kepada nasabah supaya terpikat dan loyal kepada Bank Syariah. Dalam Al-Qur'an menjelaskan bagaimana cara dakwah beliau memikat dan menjalin hubungan baik. Ayat ayat dalam Al-Qur'an diantaranya : surat Al-Ahzab ayat 21, surat Ali Imran ayat 159, dan surat An-Nahl ayat 125.

a. Surat Al-Ahzab Ayat 21

"Sesungguhnya telah ada pada (diri) Rasulullah itu suri teladan yang baik bagimu (yaitu) bagi orang yang mengharap (rahmat) Allah dan (kedatangan) hari kiamat dan Dia banyak menyebut Allah". Surat Al-Ahzab ayat 21 adalah ayat yang turun pada saat terjadinya peristiwa ahzab (perang khandak) (Qutub : 2004). Ayat ini merupakan gambaran perilaku agung Rasulullah SAW dalam perkataan, perbuatan dan perilakunya. Untuk itu, Allah SWT memerintahkan kita untuk meneladani akhlak dan sifat Rasulullah SAW dalam semua tindakannya (Abdullah :2004). 
Hikmah yang terdapat pada ayat tersebut dalam hal penerapan pelayanan di bank syariah adalah karyawan harus mencontoh akhlak Rasulullah SAW dalam semua aktifitas dalam bentuk perilaku. Perilaku baik karyawan tidak hanya diterapkan pada saat melayani para nasabahnya tetapi juga harus diterapkan pada disemua aktifitas kehidupannya. Hal ini disebabkan karena saat ini pelanggan telah menjadi sangat sensitive, satu hal kecil yang menjadi kesalahan akan mengakibatkan reaksi yang dapat mengakibatkan pada hancurmya kredibilitas perusahaan ( Gunara : 2007).

b. Surat Ali Imran Ayat 159 Artinya : "Maka disebabkan rahmat dari Allahlah kamu Berlaku lemah lembutlah terhadap mereka. Sekiranya kamu bersikap keras lagi berhati kasar, tentulah mereka menjauhkan diri dari sekelilingmu. karena itu ma'afkanlah mereka, mohonkanlah ampun bagi mereka, dan bermusyawaratlah dengan mereka dalam urusan itu. kemudian apabila kamu telah membulatkan tekad, Maka bertawakkallah kepada Allah. Sesungguhnya Allah menyukai orang-orang yang bertawakkal kepada-Nya".

Hikmah yang dapat diambil dari ayat tersebut adalah tentang penerapan pelayanan pada bank syariah diantaranya :

1. Karyawan harus mempunyai sifat lemah lembut pada saat melayani para nasabahnya. Konsep kelembutan sangat cocok dipraktekkan pada pelayanan bank syariah, karena konsep ini telah dibuktikan oleh Rasulullah dalam dakwahnya. Inilah metode marketing handal (dakwah) yang diterapkan Rasulullah SAW yang menjadikan Madinah dan Habsyi menjadi tempat kondusif untuk umat islam, padahal yang memasukkan dakwah islam pertama kali kesana adalah para sahabat, bukan Rasulullah. Akan tetapi Para sahabat ini dibekali ilmu pelayanan oleh Rasulullah SAW sehingga menjadi da'i yang unggul (Sulfiantono : 2006).

2. Karyawan juga harus menerapkan sifat pemaaf seperti yang sudah diajarkan oleh Rasulullah SAW. Sifat pemaaf bisa diterapkan dalam pelayanan perbankan syariah, contoh apabila ada nasabah yang melakukan comlain dan marah-marah karyawan harus memaklumi hal tersebut. Karyawan harus memiliki mental yang kuat, memiliki kesabaran yang tinggi dan memiliki sifat pemaaf untuk menghadapi para nasabahnya.

3. Bila ada permasalahan dengan nasabahnya harus diupayakan agar bisa diselesaikan dengan jalan musyawarah. Dengan adanya musyawarah pertikaian antara kedua belah pihak (pihak bank \& nasabah) bisa dihindarai dan diatasi.

4. Pada akhirnya karyawan harus tawakal artinya pelayanan terhadap nasabah sudah diberikan secara maksimal oleh para karyawan terkait hasilnya hanya Allah yang menentukan. Wujud dari 
tawakal tersebut disamping memberikan layanan yang maksimal juga melalui do'a kepada Allah SWT.

\section{c. Surat An-Nahl Ayat $\mathbf{1 2 5}$}

"Serulah (manusia) kepada jalan Tuhan-mu dengan Al-Hikmah dan pelajaran yang baik dan bantahlah mereka dengan cara yang baik. Sesungguhnya Tuhanmu Dialah yang lebih mengetahui tentang siapa yang tersesat dari jalan-Nya dan Dialah yang lebih mengetahui orang-orang yang mendapat petunjuk".

Hikmah yang dapat diambil dari ayat tersebut yaitu bank syariah harus menerapkan metode dakwah Rasulullah dalam menarik dan menjalin hubungan dengan nasabah. Metode dakwah tersebut yaitu Al-Hikmah, Al-Mau'idzoh bil Hasanah, Al-Mujadalah bil Hasanah (M. Zainul Wathani dan Afiati Kurniasih, 2015 : 15) :

1. Al-Hikmah yaitu menyesuaikan dakwah sesuai dengan karakter, sifat dan tingkat pemahaman objek dakwah (Abdurrahman AsSya'diy. Hal ini memiliki pengertian bahwa bank syariah harus mampu menerapkan strategi pemasaran yang sesuai dengan keberagaman nasabah. Keberagaman tersebut misalnya nasabah pelajar (mahasiswa), pengusaha, karyawan, nasabah Non-Muslim dan sebagainya. Bank syariah dalam hal ini dapat membuat program marketing (produk, harga, pelayanan) yang sesuai dengan keberagaman nasabah tersebut. Rasulullah SAW bersabda "perlakukanlah seseorang itu sesuai keadaannya masing-masing dan berkomunikasilah sesuai dengan kemampuan nalarnya" (Hasan : 2011)

2. Al-Mau'idzoh bil Hasanah memiliki pengertian nasehat yang baik. Penerapan konsep Al-Mau'idzoh bil Hasabah sangat sesuai untuk diterapkan pada nasabah yang baru mengenal perbankan. Penerapan tersebut dapat berupa pembinaan dan pendampingan nasabah, pelatihan pembuatan laporan keuangan dan sebagainya sehingga bank syariah dapat memberikan rasa nyaman kepada nasabah yang baru berinteraksi dengan bank.

3. Al-Mujadalah bil Hasanah berarti berdebat dengan cara yang baik. penerapan metode ini sangat diperlukan terutama ketika mensosialisasikan produk perbankan kepada nasabah. Para karyawan bank syariah harus mampu menjelaskan kelebihan produk bank syariah dibanding dengan produk konvensional. Penjelasan tersebut bukan hanya mengedepankan haram dan halalnya produk, tetapi juga penjelasan keunggulan produk perbankan syariah dibandingkan konvensional melalui retorika dan alasan ilmiah lainnya. Itulah mengapa perbankan syariah harus memiliki karyawan dengan keilmuan yang mumpuni, sehingga dapat menjelaskan dengan detail dan jelas keunggulan dan kelebihan produk perbankan syariah. 


\section{KESIMPULAN}

Al-Qur'an dan Al Hadist tidak hanya sebagai panduan untuk melakukan ibadah tetapi juga memberikan panduan konsep pelayanan perbankan syariah. Konsep pelayanan berdasarkan Al-Qur'an : (a) karyawan bank syariah menjadi agen pelayanan perbankan syariah harus memperhatikan 3 konsep dasar pelayanan yakni : keikhlasan, kesuaian pelayanan dengan syariat, dan berusaha melayani dengan pelayanan terbaik (sungguh-sunggguh), (b) pedoman yang terkandung dalam AlQur'an untuk memberikan pelayanan pada nasabah yakni : karyawan mencontoh Rasulullah SAW dalam melayani pelanggannya waktu berdagang, melayani nasabah dengan lemah lembut, memiliki sifat pemaaf, menyelesaikan masalah dengan musyawarah, dan memiliki tekad yang kuat dalam memberikan layanan, tawakkal terhadap hasil yang akan dicapai. Bank juga harus menerapkan metode dakwah Rasulullah SAW dalam menarik minat, dan membina nasabah yaitu Al-hikmah, AlMau'idzah bil Hasanah dan Al-Mujadalah Bil Hasanah.

\section{DAFTAR PUSTAKA}

Abdullah, Muhammad. 2008. Lubabub Tafsir Min Ibni Katsir : Tafsir Ibnu Katsir, Alih Bahasa Oleh M. Abdul Ghaffar dkk. Jakarta : Pustaka Imam Syafi'i.

Daryanto dan Ismanto Setyobudi, 2014. Konsumen dan Pelayanan Prima (Yogyakarta : Gava Media).

Departemen Agama RI, 2009. Al-Qur'anul Karim Wat-Tafsir : Al-Qur'an dan Tafsirnya jilid 10. Jakarta : Departemen Agama RI.

Finalis 1st IsEFEF, 2012. Seminar Proceeding The 1st Islamic Economic and Finance Research Forum: New Era of Indonsia Islamic Economic. Jakarta : Ikatan Ahli Ekonomi Islam (IAEI).

Firmansyah Strategi. 2016." Pelayanan Prima untuk Kepentingan Serta

Kepuasan Pelanggan dan Masyarakat", Jurnal Ilmiah Widya,Vol 3 (4), hal.163-170

Gunara, Thorik, 2007. Marketing Muhammad : Strategi Handal dan Jitu Praktek Bisnis Rasulullah SAW. Bandung : PT. Karya Kita MadaniA Prima.

Hana, K. F. (2018). Faktor-Faktor Yang Mempengaruhi Keputusan Non Muslim Menjadi Anggota Pada KSPPS Fastabiq Khoiru Ummah Pati. MALIA: Journal of Islamic Banking and Finance, 2(2), 189-200. Retrieved from http://journal.stainkudus.ac.id/index.php/syirkah/index

Hasan, Ali, 2010. Marketing Bank Syariah : Cara Jitu Meningkatkan Pertumbuhan Pasar Bank Syariah. Bogor : Ghalia Indonesia.

Malayu S. P Hasibuan, 2007. Dasar-Dasar Perbankan, (Jakarta: PT Bumi Aksara). 
Mukinim, 2011 dalam M. Zainul Wathani dan Afiati Kurniasih, 2015 ." Konsep Service Excellence Perbankan Syariah Berdasarkan AlQuran, Jurnal Nisbah Vol 1 (1), hal.1-22

M. Zainul Wathani dan Afiati Kurniasih, 2015 ." Konsep Service Excellence Perbankan Syariah Berdasarkan Al-Quran, Jurnal Nisbah Vol 1 (1), hal.1-22

Qutub, Sayyid. 2008. Tafsir fi Dzilalil Qur'an di Bawah Naungan Qur'an Jilid XII diterjemahkan oleh Ahmad Yasin dkk. Depok: Gema Insani

Rangkuti, Freddy, ANALISIS SWOT: teknik membedah kasus bisnis cara perhitungan bobot, rating dan OCAI, (Jakarta: PT gramedia)

Rahmayanty, Nina. 2013. Manajemen Pelayanan Prima, (Yogyakarta: Graha Ilmu).

Riyanto, Nur. 2012. Dasar-Dasar Pemasaran Bank Syariah, (Bandung : Alfabeta).

Sulfianto, Arif. 2006. Al-Qur'an Dan Kepuasan Pelanggan Bank Syariah, Jogjakarta : UIN Sunan Kalijaga.

Widjaya, (1951), Terjemah Hadist Shahih Bukhari, Penerjemah Zainuddin Hamidy, Bumirestu, Jakarta 